\title{
Acute kidney injury in a patient with COVID-19: Questions
}

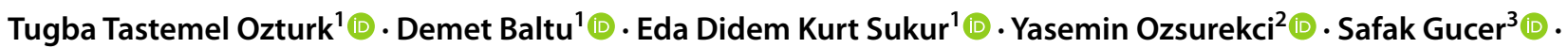

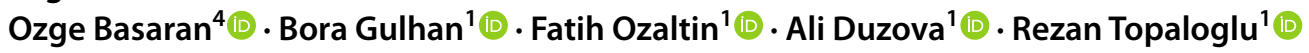

Received: 11 July 2021 / Accepted: 13 July 2021 / Published online: 7 September 2021

(c) IPNA 2021

Keywords Child · SARS-CoV-2 · COVID-19 · Acute kidney injury

\section{Case summary}

A 16-year-old girl was admitted to our hospital with chest pain, diarrhea, and swelling in the eyelids and legs. She was followed up in another hospital for behavioral problems and did not benefit from treatment. She was the third child of first-degree cousin parents; otherwise, the family history was unremarkable. On physical examination, crepitant rales, periorbital edema, and pretibial $2+$ pitting edema were found. Her blood pressure was $135 / 85 \mathrm{mmHg}$.

Laboratory findings on admission were hemoglobin $10.1 \mathrm{~g} / \mathrm{dL}$, white blood cells $6500 / \mathrm{mm}^{3}$ (absolute lymphocyte count $650 / \mathrm{mm}^{3}$ ), thrombocytes $212,000 / \mathrm{mm}^{3}$, blood urea nitrogen $33.5 \mathrm{mg} / \mathrm{dL}$, serum creatinine $2.1 \mathrm{mg} /$ $\mathrm{dL}$, uric acid $6.9 \mathrm{mg} / \mathrm{dL}$, sodium $133 \mathrm{mmol} / \mathrm{L}$, potassium $4.6 \mathrm{mmol} / \mathrm{L}$, calcium $8.9 \mathrm{mg} / \mathrm{dL}$, phosphorus $5.8 \mathrm{mg} / \mathrm{dL}$, total protein $4.4 \mathrm{~g} / \mathrm{dL}$, and albumin $1.9 \mathrm{~g} / \mathrm{dL}$. Arterial blood gas analysis showed $\mathrm{pH} 7.36$ and $\mathrm{HCO}_{3} 18.9 \mathrm{mmol} / \mathrm{L}$. Erythrocyte sedimentation rate was $52 \mathrm{~mm} / \mathrm{h}$ (normal range $0-20 \mathrm{~mm} / \mathrm{h}$ ) and C-reactive protein $2.1 \mathrm{mg} / \mathrm{dL}$ (normal range $0-0.8 \mathrm{mg} / \mathrm{dL}$ ). Urinalysis revealed an increased specific gravity (1030), proteinuria $(3+)$, and hematuria $(3+)$. Spot urine protein/creatinine ratio was $9 \mathrm{mg} / \mathrm{mg}$ and 24 -h urine

The answers to these questions can be found at http://dx.doi.org/ 10.1007/s00467-021-05237-y.

Tugba Tastemel Ozturk

t_tastemel@hotmail.com

1 Division of Pediatric Nephrology, Hacettepe University Faculty of Medicine, Sihhiye, 06100 Ankara, Turkey

2 Department of Pediatric Infectious Diseases, Hacettepe University Faculty of Medicine, Ankara, Turkey

3 Department of Pathology, Hacettepe University Faculty of Medicine, Ankara, Turkey

4 Division of Pediatric Rheumatology, Hacettepe University Faculty of Medicine, Ankara, Turkey protein $35 \mathrm{~g}$. Ultrasonography showed increased echogenicity in both kidneys. Nasopharyngeal swab polymerase chain reaction (PCR) assay was found to be positive for Severe Acute Respiratory Syndrome Coronavirus-2 (SARS-CoV-2). Thorax computed tomography (CT) showed infiltration in the lower lobe of the left lung and peripherally located nodular areas with irregular contours, and Coronavirus disease 2019 (COVID-19) pneumonia diagnosis was made (Fig. 1).

The patient was started on favipiravir and antibiotics for possible secondary bacterial infections. On the next day of hospitalization, she got more edematous and hypertensive, and her urine output decreased. Bolus methylprednisolone treatment was introduced due to the rapidly progressive course of kidney injury, and hemodialysis was started. Hypertension was controlled with volume withdrawal, amlodipine, and doxazosin treatments. Pneumonia findings gradually improved during this period; the patient's urine volume increased after 5 days of bolus methylprednisolone treatment and after four sessions of hemodialysis. On the 10th day of admission, while her nasopharyngeal swab PCR assay was still positive for SARS-CoV-2, a kidney biopsy was performed.

Kidney biopsy showed 32 glomeruli located in the cortex and corticomedullary region. There were partial or circumferential epithelial crescents in 14 glomeruli. Endocapillary proliferation, mesangial matrix increase, "wire-loop" formation, karyorrhexis, necrosis, double contour formation, and neutrophil leukocyte infiltration were observed in $90 \%$ of the glomeruli. In some crescentic glomeruli, fragmented erythrocytes and fibrin were noted (Fig. 2a, b). Tubules showed hydropic changes with erythrocytes and shed epithelial cells, lymphocytes, and neutrophil leukocytes in their lumens. Edema and patchy mononuclear inflammatory cell infiltration in the interstitium were noted (Fig. 2c). No significant microscopic pathological features were seen in the vessels. Immunofluorescence microscopy showed granular staining with $\mathrm{C} 3, \mathrm{C} 4, \mathrm{Clq}, \mathrm{IgM}$, and $\mathrm{IgG}$ in the mesangium and the basement membrane and +3 kappa and lambda in the mesangium (Fig. 2d). 
Fig. 1 Chest computed tomography images of the patient. Ground-glass opacity nodules in the right lung $(\mathbf{a}, \mathbf{b})$ and infiltration in the lower lobe of the left lung (b) are seen
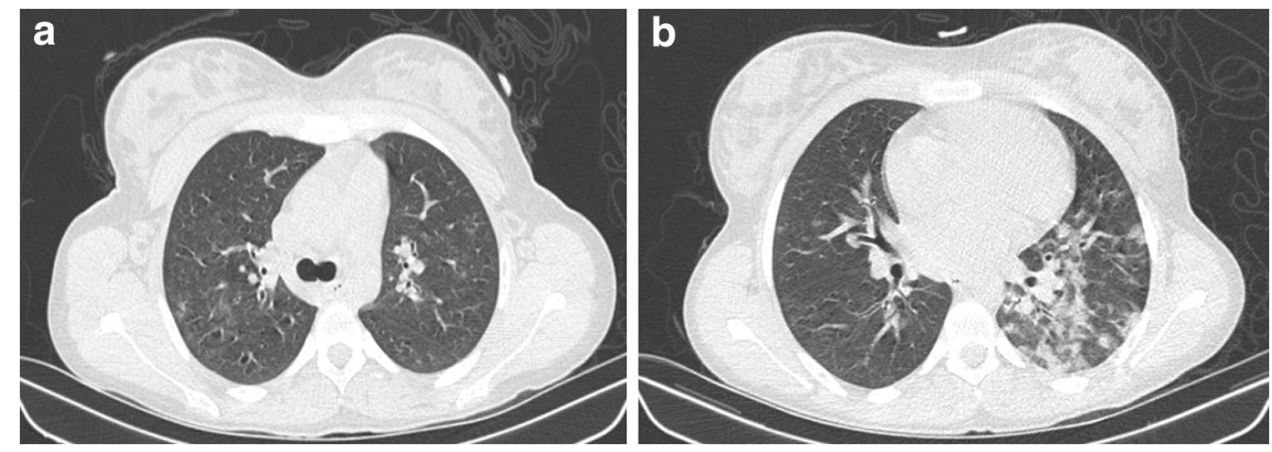
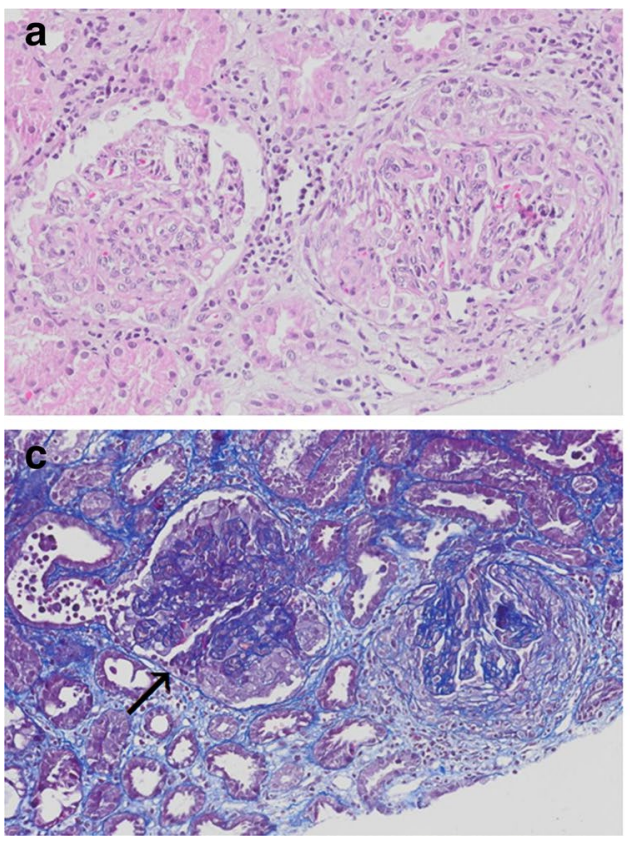

Fig. 2 Pathological findings from kidney biopsy. a Prominent endocapillary proliferation in two glomeruli and almost circular crescent formation in the right one (HE stain $\times 100)$. b The glomerular tuft is compressed by circumferential extracapillary proliferation (PAS stain $\times 200$ ). $\mathbf{c}$ There is a marked endocapillary proliferation with cellular crescents in two glomeruli. The glomerulus marked with arrow

\section{Questions}

1. What are the possible causes of acute kidney injury in this patient?

2. What additional tests would you perform?

3. What is the most likely diagnosis in this patient in view of the histopathological findings?

4. How should this patient be managed?

Data availability Not applicable.

Code availability Not applicable.
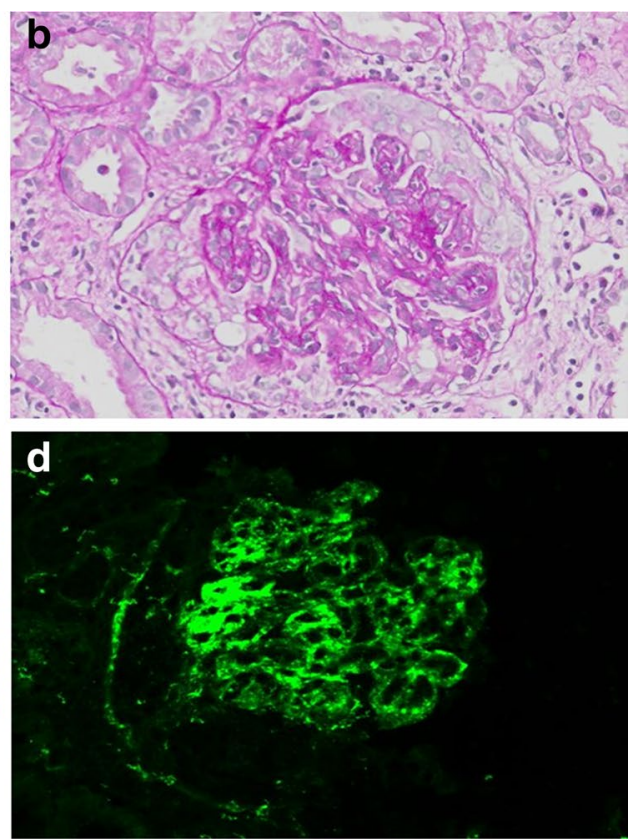

shows shed crescent cells, inflammatory cells, and necrotic material in the tubule lumen at the opening point of the Bowman capsule to the proximal tubule (Trichrome stain $\times 100$ ). d Immunofluorescence microscopy shows deposits of $\mathrm{C} 3$ in the mesangium and in the peripheral glomerular capillary walls in a global distribution

\section{Declarations}

Ethics approval Not applicable.

Consent to participate Informed consent was obtained from the parents.

Consent for publication Not applicable.

Conflict of interest The authors declare no competing interests.

Publisher's note Springer Nature remains neutral with regard to jurisdictional claims in published maps and institutional affiliations. 